\title{
A HERMENÊUTICA HEIDEGGERIANA NA PESQUISA EM CLÍNICA
}

\author{
HEIDEGGERIAN HERMENEUTICS IN CLINICAL RESEARCH
}

\author{
Melina Séfora Souza Rebouças ${ }^{1}$ \\ Elza Dutra ${ }^{2}$
}

\begin{abstract}
Resumo: O trabalho é um ensaio teórico fruto da tese de doutorado da autora e tem como objetivo pensar a hermenêutica heideggeriana como método na pesquisa em clínica. Para essa perspectiva, os fenômenos somente são vistos na própria existência e em sua sedimentação histórica fática, enquanto método referese a um caminho para o desencobrimento dos fenômenos via círculo hermenêutico. Desse modo, tanto a clínica quanto a pesquisa buscam destecer a trama existencial à qual o homem encontra-se aprisionado, acompanhando o próprio movimento da existência. A hermenêutica heideggeriana mostra-se de grande importância para as pesquisas clínicas, na medida em que não busca uma verdade universal, e, sim, compreensões acerca dos fenômenos, as quais não podem ser representadas, apenas acompanhadas e desveladas.
\end{abstract}

Palavras-chave: Hermenêutica Heideggeriana; Pesquisa em Clínica; Clínica Fenomenológico-Existencial.

\begin{abstract}
This work is a theoretical essay from the author's doctoral thesis, whose aim to think the Heideggerian hermeneutics like a method in the clinical research. According to this perspective, phenomena are only seen in the very existence and its historical horizon. And method refers to a path to uncover the phenomena via the hermeneutical circle. In this way, both clinic and research seek to unweave the existential plot which man is imprisoned following the very movement of existence. The Heideggerian hermeneutics it is of great importance for clinical research, in that it does not seek an universal truth but rather understandings about phenomena; and these, as understandings, can not be represented, only accompanied and unveiled.
\end{abstract}

Keywords: Heideggerian Hermeneutics; Clinical Research; Phenomenological-Existential Clinic.

\section{Introdução}

O presente trabalho consiste em um ensaio teórico fruto da tese de doutorado intitulada "Aborto: um fenômeno sem lugar - uma experiência de plantão psicológico para mulheres em situação de abortamento" (REBOUÇAS, 2015) e cujo objetivo é pensar a respeito da hermenêutica heideggeriana como método na pesquisa em psicologia clínica. Inicialmente, faremos algumas considerações sobre pesquisa fenomenológica, realizando um apanhado histórico do desenvolvimento desse método, bem como de suas

\footnotetext{
${ }^{1}$ Doutora em Psicologia pela Universidade Federal do Rio Grande do Norte (UFRN). Integrante do Grupo de Estudos Subjetividade e Desenvolvimento humano GESDH/UFRN, Natal, RN, Brasil. E-mail: melina_sefora@yahoo.com.br

${ }^{2}$ Doutora em Psicologia pela Universidade de São Paulo (USP). Professora Titular da Universidade Federal do Rio Grande do Norte (UFRN), Natal, RN, Brasil. E-mail: elzadutra.rn@gmail.com
} 
principais ideias e pensadores. Posteriormente, iremos nos debruçar sobre a hermenêutica tal como compreendida pelo filósofo Martin Heidegger, focando na discussão acerca de como esse modo de pensar pode contribuir para nos aproximarmos dos sentidos das experiências humanas, objetivo das pesquisas de cunho fenomenológico.

\section{Algumas considerações sobre pesquisa fenomenológica}

A fenomenologia é um pensamento que se apresenta como uma epistemologia, uma filosofia e um método, tendo suas origens no pensamento de Edmund Husserl (18591938). Enquanto epistemologia, ela se preocupa com a possibilidade do conhecimento, isto é, com o modo como se fundamenta o conhecimento e em que bases ele se dá. Como filosofia, a fenomenologia propõe uma reflexão sobre a realidade e busca uma forma de acessá-la, respectivamente. A grande proposta de Husserl era oferecer uma nova forma de conhecer o mundo; para tanto, partiu de uma crítica às ciências naturais, promovendo uma ruptura com a tradição epistemológica, cujo pensamento baseava-se na separação sujeito-objeto. A grande crítica da fenomenologia à ciência é que esta não leva em consideração o ser humano. A fenomenologia, portanto, valoriza a experiência humana, colocando o sujeito e o objeto em uma relação indissociável. Esse modelo de pensamento busca apreender as relações do homem com o mundo por meio da relação entre consciência e experiência (HOLANDA, 2014).

A consciência, no pensamento de Husserl, é dotada de uma intencionalidade, isto é, a consciência é sempre consciência de algo. A partir dessa perspectiva, é a consciência que estabelece a relação entre os objetos e entre o sujeito e o mundo. $\mathrm{O}$ homem encontrase entrelaçado com o mundo. Nesse sentido, a consciência não é uma entidade psíquica ou uma estrutura da personalidade, mas abertura, ato, vivência. De acordo com Sá (2017), em uma atitude natural, acredita-se que as coisas existem por si mesmas, independentemente da sua relação com a consciência, assim, o que uma atitude fenomenológica propõe é ater-se ao fenômeno tal como se dá à experiência. Nesse contexto, o objetivo da fenomenologia enquanto método de apreensão da realidade é "voltar às coisas mesmas".

Para Goto (2008), Husserl acreditava ser possível intuir a essência de um fenômeno propondo um retorno às coisas mesmas, isto é, deixar ver, por si mesmo, o que aparece na experiência imediata, sem o olhar das teorias científicas e filosóficas préestabelecidas. Holanda (2014) afirma que "voltar às coisas mesmas" significa ter sobre o 
mundo um olhar ingênuo, observar o fenômeno tal qual ele aparece, sem o nosso crivo reflexivo. Nessa forma de pensar, o acesso ao fenômeno somente se dá via intuição, e não via pensamento conceitual, como evidencia Holanda (2014, p. 52): “[...] o logos, o sentido, não está nas teses previamente formadas a respeito de determinado fenômeno, mas está no próprio fenômeno [...]".

Ao deixar o fenômeno mostrar-se tal qual ele é, sem nenhuma representação ou teoria prévia, realiza-se, segundo o pensamento husserliano, uma redução/suspensão fenomenológica ou epoqué. A epoqué refere-se à atitude de "colocar entre parênteses" ideias, juízos, valores e conceitos para se aproximar da essência do fenômeno. Husserl propõe, portanto, a saída de uma atitude natural para uma atitude fenomenológica. Sobre essa questão, Sá e Barreto (2011, p. 390) expõem:

\begin{abstract}
A expressão "atitude natural" denomina nossa tendência de tomar todas as coisas que encontramos no mundo como se já sempre estivessem dadas aí, indiferentes à nossa relação de sentido com elas. O próprio sujeito é tomado como algo dado dentro de um mundo pré-existente a ele. A diferença entre o modo de ser do sujeito e o das outras coisas restringe-se, a partir de uma ontologia cartesiana, em ter ou não uma natureza extensa, mas, para aquém desta diferença, ambos são ainda simplesmente dados dentro do mundo. Colocar-se numa perspectiva fenomenológica é suspender essa suposição "natural" de uma realidade "em si", realizar uma epoché, retornando para as coisas apenas enquanto dadas à experiência.
\end{abstract}

Em face dessas ideias, Husserl faz uma crítica às consideradas ciências humanas, por fazerem uso do método naturalista. Este filósofo acredita que o ser humano não pode ser tomado em sua aparência empírica como um objeto, mas enquanto vivência. Essa crítica é direcionada principalmente para a psicologia, cuja tentativa era tomar o psiquismo como determinado a priori. Para Husserl, a psicologia deveria se voltar para o caráter intencional dos fenômenos psíquicos.

Segundo Feijoo (2011), para a fenomenologia de Husserl, o psiquismo não pode ser determinado previamente, o eu não é visto enquanto uma interioridade e a consciência não se fecha em si mesma, mas se projeta para o mundo. Nessa perspectiva, o homem é tomado como um fluxo de vivências. Husserl afirmava que a psicologia é uma ciência empírica, isto é, que busca conhecer os fatos, no entanto, este propôs que a psicologia empírica deveria ser precedida por uma psicologia eidética. Uma psicologia eidética iria além dos fatos e estaria interessada na significação desses fatos, ou seja, pretenderia acessar as relações e as significações presentes nessas relações (RAFAELLI, 2004).

A partir das ideias husserlianas, a fenomenologia passou a ser utilizada como método de apreensão da realidade por várias ciências, principalmente pela psicologia. De 
forma geral, uma pesquisa de base fenomenológica busca o significado da realidade e do mundo a partir da vivência do próprio sujeito, considerando que ele é o ponto de acesso à essência dos fenômenos. No entanto, cabe alertar que a vivência do sujeito não significa ver o mundo sob a sua ótica "singular/particular", pois isso equivaleria a um subjetivismo. Captar a essência das vivências concerne a encontrar nas particularidades aquilo que é fundante ou essencial para a manifestação de um determinado fenômeno. A esse respeito, Holanda (2014), citando um exemplo de Husserl sobre a IX sinfonia de Beethoven, indaga-se: por que reconhecemos a sua melodia mesmo quando esta muda sua forma? Ele mesmo responde que a reconhecemos porque sua essência permanece mesmo que mudassem os ritmos ou até mesmo que suas partituras, orquestra e ouvintes desaparecessem.

A pesquisa fenomenológica apresenta como principais características: buscar a essência do fenômeno estudado; enfatizar a relação pesquisador-pesquisado; acessar o fenômeno no próprio ato da relação; e identificar o sentido da experiência (HOLANDA, 2003). A pesquisa de caráter fenomenológico visa, portanto, uma compreensão das relações entre homem e mundo, isto é, uma compreensão do mundo vivido.

Nesse entendimento, trabalhar com a experiência vivida é tomar o relato do sujeito em sua intencionalidade constitutiva. Esse tipo de pesquisa se interessa pela experiência cotidiana imediata em que todos nós vivemos, a qual se revela na própria relação pesquisador-pesquisado. A pesquisa fenomenológica preocupa-se com os fundamentos da significação presentes nessa relação, ou seja, com o sentido, como pensa Dutra (2002). Assim, objetiva-se realizar não uma verificação, mas uma compreensão do fenômeno. A ideia é que por meio da compreensão seja possível nos aproximarmos do fenômeno em questão, evitando, assim, as explicações que podem nos afastar daquilo que se mostra e levando-nos somente aos fatos (AMATUZZI, 2003). Lembramos que, de acordo com Holanda (2003), fato é tudo aquilo que pode ser estudado de forma objetiva e rigorosa, enquanto os fenômenos mostram-se por si mesmos.

Amatuzzi (2003, p. 21) pontua que a pesquisa fenomenológica tem como intuito "surpreender o vivido no presente, quando a experiência da pessoa é pensada de repente e dita como que pela primeira vez [...]". Tal aproximação do vivido exige do pesquisador abertura e disponibilidade para ir ao encontro do outro e tentar compreendê-lo em seu desvelamento. Essa abertura do pesquisador, ao facilitar a expressão do outro, torna a entrevista fenomenológica mobilizadora e, em grande parte, interventiva, na medida em que o próprio pesquisado revê sua experiência e constrói novos significados. 
É importante ressaltar que não existe somente um modelo de pesquisa fenomenológica em psicologia, mas vários, em virtude das diversas formas pelas quais ela é pensada, embora estas possuam um núcleo comum, qual seja: buscar o significado da experiência (ANDRADE; HOLANDA, 2010). Dentre os autores que mais se destacaram na fenomenologia, além de Husserl, estão Merleau-Ponty, Sartre e Heidegger.

A adaptação mais conhecida do método fenomenológico de Husserl para a psicologia foi desenvolvida por Amedeo Giorgi, cujo modelo é chamado de fenomenológico empírico. Esse tipo de pesquisa visa acessar o vivido a partir de dados empíricos e da análise de depoimentos. Trata-se de uma descrição das experiências vividas das pessoas a respeito de um determinado fenômeno, buscando os elementos invariantes do discurso com o objetivo de chegar a um significado central ou "essencial" (ANDRADE; HOLANDA, 2010). Outro tipo de pesquisa fenomenológica é a eidética, utilizada por autores como Karl Jaspers, Sartre e Merleau-Ponty, a qual se propõe a realizar uma elucidação do vivido mediante a redução fenomenológica. A pesquisa com base na fenomenologia hermenêutica parte dos princípios propostos pelo filosofo Martin Heidegger, discípulo de Husserl, sobre o círculo compreensivo ou hermenêutico (HOLANDA, 2003).

A seguir, detalharemos a proposta hermenêutica de Heidegger e refletiremos sobre como podemos pensá-la enquanto método de investigação nas pesquisas em psicologia clínica.

\section{Hermenêutica heideggeriana e pesquisa em clínica}

O filósofo alemão Martin Heidegger (1889-1976) é conhecido como um pensador à frente do seu tempo por questionar toda a tradição do pensamento metafísico e redimensionar o problema do ser. Segundo esse filósofo, a tradição metafísica promoveu o esquecimento do ser ao tentar defini-lo, isto é, sempre pensou sobre o ser como algo dado, encapsulado, fechado. Além disso, ao substancializar e entificar o ser, ela deixou de pensar o seu sentido originário e fundante. Desse modo, Heidegger não pergunta o que é o ser, como fez o pensamento metafísico, mas questiona sobre o seu sentido, na medida em que o ser é sempre possibilidade, não podendo ser determinado aprioristicamente.

Em sua principal obra, Ser e Tempo, publicada em 1927, Heidegger retoma a questão do ser e realiza uma analítica da existência a partir do método fenomenológico, 
definindo-o como: “[...] deixar e fazer ver por si mesmo aquilo que se mostra, tal como se mostra a partir de si mesmo. É este o sentido formal da pesquisa que traz o nome de fenomenologia" (HEIDEGGER, 2005, p. 65)․․ Em sua analítica, o autor visa mostrar outra forma de compreender os fenômenos e, com isso, fornecer um método mais adequado para as ciências humanas, continuando o trabalho do seu mestre, Edmund Husserl (1859-1938).

Heidegger define o modo de ser do homem como Dasein ou Ser-aí, expressão que significa compreender o homem enquanto um ser-no-mundo, isto é, homem e mundo possuem uma relação de inseparabilidade. Nessa perspectiva, estar no mundo não significa estar dentro do mundo, mas estar envolvido em uma trama de significados sempre historicamente em movimento. O homem, então, é um ser lançado, um ser de abertura, que nunca pode ser delimitado ou estático. Nessa abertura, o homem é um sercom, um ser de relação; ele nunca está sozinho. Ao estar no mundo, o homem se depara com a sua facticidade, que significa encontrar-se em determinado corpo e envolvido por determinadas condições como história, cultura e valores. A facticidade, apesar de fazer parte da constituição dos modos de ser do homem, não o determina, devido à sua condição existencial de abertura e movimento.

O método fenomenológico proposto por Heidegger busca o redimensionamento da questão do ser em sua proximidade com a práxis humana como existência e facticidade (STEIN, 1983; CASANOVA, 2009). É nesse ponto que se encontra a diferença da fenomenologia transcendental de Husserl para a fenomenologia hermenêutica de Heidegger. De acordo com Casanova (2009), o que Husserl não levou em consideração foi a existência de um estrato mais original do que a subjetividade transcendental, a facticidade. Desse modo, o fenômeno passa a ser visto na própria existência, que considera a sua sedimentação histórica fática e não somente a partir das relações imanentes da consciência pura com os seus campos objetais. Os entes se mostram como entes que são neste horizonte fático, como pontua Casanova (2009, p. 47):

Esse horizonte possui, além disto, um caráter histórico sedimentado. Ele não se determina de maneira lógico-transcendental a partir das relações imanentes à consciência pura, mas se constrói historicamente a partir de decisões de pensamento que vão paulatinamente determinando o que se mostra ou não como dotado de sentido.

Partindo do pensamento heideggeriano, a facticidade deve ser assumida enquanto óbvia e não suspendida, pois a suspensão proposta por Husserl não é capaz de retirar o

\footnotetext{
${ }^{3}$ Original de 1927.
} 
homem dessa sedimentação fática. Para Husserl, o que está fora são os atos intencionais ou o conhecimento intuitivo, enquanto, para Heidegger, é o próprio Dasein enquanto serno-mundo, o que significa que o conhecimento não é algo que se dá separado do Dasein. A possibilidade de conhecer somente existe devido à condição ontológica de coexistência homem-mundo (ROEHE, 2005). Nesse referencial, o mundo não diz respeito à natureza, mas, sim, a uma trama de significados que envolve a coexistência com o homem, o mundo, as coisas e os outros. Desse modo, os significados não estão nas coisas e as coisas não existem em si mesmas, e sim no mundo, isto é, somente se manifestam a partir dessa trama, que é existencial. Os significados, portanto, somente podem pertencer à existência e não à coisa em si, como propõe o pensamento metafísico (CRITELLI, 1996).

O conhecimento, apoiado no modo de ser do homem, exige uma nova metodologia que não se baseie no pensamento lógico-conceitual, mas na dimensão elucidativa e reveladora do ser, isto é, uma metodologia apoiada na condição e na experiência humana (CRITELLI, 1996). É nesse ponto que o pensamento fenomenológico traz grandes contribuições para a pesquisa nas ciências humanas e, principalmente, para a psicologia, como veremos adiante.

Por esse viés, investigar ações humanas vai além desses instrumentais e orientase pelo próprio homem em seu estar-sendo-no-mundo. Diferentemente do pensamento metafísico, que funda sua investigação na precisão metodológica do conceito/representação, a fenomenologia a funda no próprio mundo, na existência humana mesma, entendida como coexistência em seus modos de ser no mundo e no movimento de vir-a-ser do existir (CRITELLI, 1996).

Nesse pensamento, Heidegger propõe que o conhecimento se dê como Alétheia e não como Veritas, o que significa que ele acontece como des-encobrimento, desvelamento, não tendo como objetivo a busca de uma verdade. Tanto Alétheia (origem grega) como Veritas (do latim) são traduzidas como verdade, embora possuam sentidos diferentes. A primeira significa desvelamento, desocultação, trazer à luz, já o segundo se refere à verdade enquanto conhecimento verificável, aquilo que pode ser representado (BARRETO, 2013; POMPÉIA; SAPIENZA, 2004). Heidegger (2005) evidencia que o conceito tradicional de verdade consiste na concordância ou adequação de um conhecimento ao seu objeto, entretanto, no seu pensamento, a verdade é o ser e o estar descoberto do próprio ente. A verdade é o que se deixa ver a partir de si mesmo, ou seja, aquilo que se desvela. Em outras palavras, a verdade é uma apresentação das coisas, e não uma representação. 
Para Heidegger (2009), o método nas ciências é o modo pelo qual a pesquisa procede no exame do seu objeto. É um procedimento cujo objetivo é dominar/representar a natureza. No entanto, o autor considera que existem coisas que resistem à medição/representação, as quais, no máximo, podemos tematizar. Por esse viés, método não diz respeito a um procedimento, mas à maneira como o ente é tematizado. O método em seu modo de pensar é compreendido como um "envolver-se", um "caminho para":

[...] parece-me necessário, como indicação de nosso método totalmente diferente, o nome "envolver-se especialmente em nossa relação com o que encontro", em que já nos encontramos sempre. Num certo sentido, faz parte da fenomenologia $\mathrm{o}$ ato de vontade de não se fechar contra este envolver-se. [...] O envolver-se é um caminho inteiramente diferente, um método muito diferente do método científico, se soubermos usar a palavra método em seu sentido original, verdadeiro, o "caminho para" ... A esse respeito os senhores precisam afastar-se do conceito comumente de método enquanto uma simples técnica de pesquisa (HEIDEGGER, 2009, p. 148).

Segundo Heidegger (2013a) ${ }^{4}$, a expressão fenomenologia não significa uma corrente de pensamento ou um ponto de vista, mas antes um conceito de método que se volta para o como e não para o que dos objetos. Sua preocupação é levar o ser à revelação, desvelando as estruturas do Dasein. As possibilidades do Dasein encontram-se encobertas em seu cotidiano e o seu des-encobrimento dá-se a partir da hermenêutica, a qual será discutida a seguir. A proposta heideggeriana de buscar as coisas mesmas referese, portanto, ao desobscurecimento da sedimentação histórica em que o Dasein vive para que assim as bases ontológicas dos fenômenos apareçam.

Nesse sentido, o pensamento heideggeriano contrapõe-se ao modo de conhecimento cartesiano, calcado no controle e na previsibilidade dos fenômenos representados de maneira estável e universal. O conhecimento com base nas ideias heideggerianas apoia-se na própria experiência humana do existir, considerando a sua inospitalidade e mutabilidade. Assim, qualquer conhecimento a respeito do homem é, para essa perspectiva, relativo. Conforme Critelli (1996, p. 13), “do ponto de vista fenomenológico, a relatividade da perspectiva do saber e da verdade abre-se como ponto inseguro, mas próprio do existir (ser)".

Critelli (1996) expõe que a tradição cartesiana sempre procurou o ser das coisas no conceito/representação, enquanto a fenomenologia o busca na própria trama existencial do ser-no-mundo. O ser somente pode ser compreendido se revelado em seu horizonte existencial e o homem é o único ente cujo modo de ser é capaz de modalizar

\footnotetext{
${ }^{4}$ Original de 1927.
} 
seu ser em infinitas possibilidades. Diferentemente do animal, ao qual a possibilidade de ser já está dada, resolvida ao nascer, o ser do homem aparece como um problema, uma questão, qual seja: a de estar sob sua responsabilidade cuidar de ser.

Esse fato significa que o homem é o único ente capaz de perceber a sua própria manifestação. O homem se manifesta compreendendo a sua manifestação e a dos demais entes. O ser do homem está imerso e envolvido por essa trama que é a coexistência, sendo esta quem possibilita o compreender e, consequentemente, o conhecer. Nesse sentido, a condição para que algo seja visto e conhecido é a coexistência com os outros. Então, ao desvelarmos um fenômeno, o que aparece é uma das suas muitas possibilidades, manifestadas a partir daquela relação. Considerada essa relação, quando algo é visto e ouvido por outros, é testemunhado. Esse outro, ao testemunhar, também se manifesta, isto é, aparece e se ilumina, conforme aponta Critelli (1996): “o aparecimento da coisa compreendida é simultaneamente o aparecimento daquele que compreendeu" (p. 79).

Diante dessas considerações sobre a analítica existencial, o método proposto por Heidegger na busca da verdade como Alétheia é o hermenêutico. É a hermenêutica que possibilita a manifestação do ser do ente, clareando a compreensão do existir do homem em sua concretude, como explica o próprio filósofo:

\begin{abstract}
A hermenêutica tem como tarefa tornar acessível o ser-aí próprio em cada ocasião em seu caráter ontológico do ser-aí mesmo, de comunicá-lo, tem como tarefa aclarar essa alienação de si mesmo de que o ser-aí é atingido. $\mathrm{Na}$ hermenêutica configura-se ao ser-aí como uma possibilidade de vir a compreender-se e de ser essa compreensão (HEIDEGGER, 2013b, p. 21). ${ }^{5}$
\end{abstract}

Segundo Melo (2013), a hermenêutica é compreendida por Heidegger não como ato de interpretar, mas como ato de trazer uma mensagem, anunciar, dar notícia. A hermenêutica, portanto, refere-se à condição do homem de ser mensageiro.

A tradição hermenêutica sugere que primeiro interpretemos para depois compreendermos, costumando ser referida como a arte da interpretação, ou seja, como um método utilizado pela ciência para entender textos ou experiências. Todavia, Heidegger não considera a compreensão como uma função cognitiva, da mesma maneira que não concebe um método/técnica em seu sentido usual, como um meio para se chegar a um fim. Para esse filósofo, a compreensão é uma condição do existir humano; o homem existe a partir da compreensão, ela é o próprio ser-no-mundo enquanto abertura. Dessa forma, a compreensão não está a serviço de um saber nem pode ser visada, pois ela diz respeito à experiência do homem no mundo e, portanto, somente pode ser acompanhada

\footnotetext{
${ }^{5}$ Original de 1923.
} 
e desvelada, como explicita Heidegger (2013b) nesta passagem: “A hermenêutica não é um modo artificialmente concebido de análise que é imposta ao ser-aí e perseguido por curiosidade. Se considerado a partir da própria facticidade, deve-se determinar quando e em que medida ela solicita a interpretação proposta" (p. 21).

De acordo com Melo (2013), a fenomenologia é hermenêutica, uma vez que busca o desvelamento do sentido do ser e de suas estruturas fundamentais. Em outras palavras, ela torna possível a elucidação do que Heidegger denomina de existenciárias ou existenciais. O Dasein, enquanto ser de abertura, possui como principais estruturas existenciais a compreensão, a disposição e o discurso. Essas estruturas se referem à condição de possibilidade do existir humano, sendo características ontológicas, ou seja, constitutivas do Dasein.

Heidegger (2005) considera a compreensão uma característica fundamental da existência humana, condição de possibilidade do existir humano. Diante disso, o Dasein (ser-aí), enquanto abertura/poder-ser, compreende a si mesmo por meio da sua relação com o mundo, assumindo determinada possibilidade a partir do seu aí. A esse respeito, Melo (2013, p. 90) afirma:

O ser-aí não tem uma compreensão, mas, ao contrário, ele é a partir da compreensão, na medida em que compreensão é a abertura imediata de possibilidades interpretativas existenciais do ser-aí e de seu mundo. Mundo diz respeito, portanto, a condições compreensivas existenciais do interpretar ele mesmo, nas quais o existente humano sempre já está inserido.

Desse modo, a compreensão abre um horizonte de sentido que consolida determinadas possibilidades existenciais, a partir das quais o homem irá se comportar e se relacionar. No intuito de entendermos melhor essas ideias, recorremos a um outro existencial: disposição afetiva ou Befindlichkeit, a partir do qual se encontra disposto um humor ou uma coloração afetiva que indica como uma pessoa está ou como ela vai, também entendido como sentimento, como aponta Dutra (2016). Tal humor, então, passa a influenciar a nossa percepção sobre algo. Portanto, todos nós possuímos uma précompreensão das coisas que foi predisposta pelo nosso humor. Por esse viés, Heidegger (2005, p. 188) afirma: “O humor revela 'como alguém está e se torna'. É nesse 'como alguém está' que o humor conduz o ser para o seu 'pre"'. As coisas e os outros que vêm ao nosso encontro no mundo passam a nos afetar e dessa afetação é possível haver uma compreensão, conforme comenta Heidegger (2005, p. 192): "Na disposição subsiste existencialmente um liame de abertura com o mundo, a partir do qual algo que toca pode vir ao encontro". 
Nesse sentido, a hermenêutica heideggeriana parte da nossa compreensão prévia, advinda das nossas relações com o mundo, para realizar uma interpretação sobre os fenômenos. A interpretação é uma elaboração/apropriação do que foi compreendido, pois, na perspectiva de Heidegger (2005), o mundo já compreendido se interpreta, sendo a interpretação fundada existencialmente no compreender. A partir dessa interpretação advinda da compreensão, as coisas que vêm ao nosso encontro podem ser descobertas, e quando isso ocorre temos o sentido.

Retomando o que foi citado, a compreensão é constitutiva do ser-aí e se dá em um horizonte experiencial da existência, o qual está marcado pelo caráter incontornável da abertura do ser, sua historicidade e finitude. Em face desse horizonte existencial, estamos sempre nos afetando e dessa afetação nós compreendemos, interpretamos e elaboramos sentidos para as coisas que vêm ao nosso encontro no mundo e por meio das quais fazemos nossas escolhas. Devido à abertura do Dasein, esse movimento da compreensão não para e acontece em uma circularidade, estabelecendo o que Heidegger denomina de situação hermenêutica, que se constitui em três momentos: posição prévia, visão prévia e concepção prévia (REBOUÇAS, 2010).

A posição prévia é a compreensão característica de um determinado contexto pelo fato de o homem sempre se encontrar nele e estar por ele envolvido; seria a apreensão da situação como uma totalidade. A visão prévia refere-se a um recorte ou a um desentranhamento do que será compreendido do seu contexto habitual, isto é, pouso minha visão sobre o aspecto que desejo interpretar. Por fim, a concepção prévia trata-se das conceituações advindas do que foi recortado, as quais já se encontram presentes em qualquer compreensão (HEIDEGGER, 2005).

A circularidade compreensiva promove o aparecimento/desvelamento do sentido dos fenômenos a partir do horizonte existencial em que o homem se encontra e daquilo que passa a ser questão para ele e que o move na busca compreensiva. Esse desvelamento se dá através da palavra, isto é, da linguagem/discurso.

Heidegger (2005) pontua que a linguagem é a morada do ser, ou seja, o homem habita na linguagem, a qual se refere à articulação entre a afetação e a compreensão. É através da linguagem que o discurso se pronuncia, que o homem fala e escuta. A fala sempre envolve a escuta, dada a condição de ser-no-mundo-com-os-outros, pois a fala somente acontece se tiver alguém para ouvi-la, como explica o referido filósofo: 
Escutar é o estar aberto existencial da pre-sença ${ }^{6}$ enquanto ser-com os outros. Enquanto escuta da voz do amigo que toda pre-sença traz consigo, o escutar constitui até mesmo a abertura primordial e própria da pre-sença para o seu upoder-ser mais próprio. A pre-sença escuta porque compreende (HEIDEGGER, 2005, p. 222).

A fala/escuta, portanto, expressa os sentidos articulados na compreensibilidade. Essa trama de sentidos constituída irá compor o habitar do homem, o lugar ao qual pertence, com o qual se familiariza e compartilha com os outros em sua coexistência.

Após as explicitações sobre a hermenêutica heideggeriana, faz-se importante salientar que sua proposta não foi pensada para ser usada em um contexto de pesquisa, uma vez que diz respeito a uma ontologia ${ }^{7}$, cuja analítica procura trazer uma aproximação do sentido do ser. Nessa perspectiva, buscamos na hermenêutica heideggeriana uma inspiração para pensar sobre as questões do humano em seu cotidiano, isto é, no plano ôntico ${ }^{8}$. A fenomenologia hermenêutica na pesquisa e na clínica, portanto, não é utilizada como teoria aplicada, mas possibilita, tanto na investigação quanto na experiência clínica, uma reflexão a partir de pressupostos que não sejam metafísicos, e, sim, ontológicos.

Esse esforço vem sendo realizado na psicologia por estudiosos como Critelli (1996), Feijoo (2010), Dutra (2002), Frota (2010), Morato (2009), Azevedo (2013) e Maux (2014), cuja preocupação não é a de sistematizar um método propriamente dito, mas de dialogar com a hermenêutica, de modo a ter, assim como propõe Heidegger, um novo olhar sobre os fenômenos.

Tal maneira de pensar traz grandes contribuições para a pesquisa em psicologia clínica, na medida em que não transforma esse campo em objeto de estudo, mas passa a compreendê-lo enquanto um processo construído a partir do encontro de um Dasein com outro Dasein, não havendo uma separação entre pesquisador/pesquisado ou psicólogo/cliente, estando ambos envolvidos pelas mesmas determinações ontológicas. É justamente nessa relação que as coisas e os outros aparecem, isto é, que um conhecimento sobre um determinado aspecto da realidade emerge. O homem é sempre condição para que algo seja visto.

A clínica psicológica é cotidianamente compreendida como uma aplicação prática das teorias psicológicas e a pesquisa, como a criação de procedimentos para aproximação de uma realidade. Nesse sentido, ambas, clínica e pesquisa, são tomadas em termos de

\footnotetext{
${ }^{6}$ Uma das traduções de Dasein.

${ }^{7}$ Ontologia se refere ao estudo do ser em geral e em suas infinitas possibilidades. O ontológico permite a manifestação do ôntico.

${ }^{8}$ Ôntico concerne ao estudo do ente em sua existência concreta, cotidiana.
} 
método, seja método de intervenção, seja método de investigação. $\mathrm{O}$ método para a ciência moderna trata-se de um caminho seguro que possui um ponto de partida e um ponto de chegada, contudo, para a fenomenologia, representa um caminho que se faz no próprio caminhar, isto é, ele vai sendo construído ao longo do processo psicoterápico ou do processo investigativo (SÁ, 2002). O rumo do aspecto da realidade que se intenciona conhecer passa a ser tomado pelo próprio movimento do mostrar-se e ocultar-se da existência.

Para Heidegger, o método coincide com o movimento do pensamento, pertencendo à própria questão, ou seja, é determinado por aquilo que se deseja saber (STEIN, 1983). Mediante essa condição, pode-se mencionar que a bússola ou a direção de um processo investigativo é dada pela questão que mobiliza o pesquisador, bem como pela relação estabelecida com o fenômeno pesquisado. É nessa coexistência que irão surgir os possíveis caminhos de como pesquisar um determinado fenômeno que é singular. Trata-se de uma construção que se dá no próprio percurso da pesquisa, seguindo a questão que norteia o pesquisador e o movimento do próprio fenômeno (CABRAL; MORATO, 2013).

Dessa feita, o conhecimento e as compreensões produzidas são apenas algumas das interpretações possíveis sobre um determinado fenômeno, uma vez que dependem do contexto e da singularidade dos envolvidos. O objetivo do método fenomenológico hermenêutico não é encontrar um conhecimento que possa ser representado, e, sim, compreensões, na medida em que este não se guia pela razão/conteúdo, mas pela afetação/sentido, sendo sempre contextual, relativo, provisório e singular. A esse respeito, Cabral e Morato explicitam (2013, p. 180):

Assumimos, portanto, a produção do conhecimento como um processo de
construção de compreensões acerca dos fenômenos, que ocorrem na
interlocução do pesquisador com o que ou o quem é pesquisado, importando,
sobretudo, o modo como esses encontros ocorrem. Tal perspectiva valoriza a
própria experiência entre humanos - a coexistência - como lócus primordial
para a elaboração de sentido no contexto da existência, implicando afetações,
mobilizações, desalojamentos.

Pesquisa e clínica, na perspectiva fenomenológica hermenêutica, acompanham o próprio movimento da existência e rumam na direção dos sentidos dos fenômenos a partir da experiência. Sob essa ótica, em nosso entendimento, trazer a hermenêutica heideggeriana para a realidade de uma pesquisa clínica significa almejar compreender como uma pessoa se situa no mundo, como ela lida com algo naquele momento; na verdade, a compreensão traduz o nosso próprio modo de ser (REBOUÇAS, 2010; 
REBOUÇAS; DUTRA, 2012). Nesse contexto, uma pesquisa hermenêutica não busca fatos, mas modos de ser. Ao entrar em contato com a experiência narrada, possibilita uma ampliação da compreensão desses modos de ser.

O pesquisador, durante uma entrevista, não procura uma resposta definitiva para o seu questionamento, ele intenciona uma aproximação do sentido da experiência do entrevistado, lembrando que esse sentido se deu a partir do próprio encontro ali estabelecido, portanto, possui toda a estruturação prévia do pesquisador e do pesquisado. A hermenêutica exige do pesquisador não uma consciência dos seus valores, mas uma abertura (que, enquanto um ser-no-mundo, já o constitui) para nada além do que a sua própria disposição de ser afetado lhe permite. A partir daí, abre-se o horizonte da précompreensão, da compreensão, da interpretação e, por fim, do sentido (FERREIRA, 2009).

Feijoo (2011), ao comentar sobre a situação clínica, afirma que o psicólogo não é neutro/puro, pois, no encontro com o outro, sua história também se faz presente. Desse modo, em uma postura hermenêutica, faz-se necessário considerar os horizontes históricos sedimentados pelo psicólogo e pelo cliente, já que é na fusão desses horizontes que o fenômeno ou o outro irá aparecer. Com base nesse entendimento, segundo a autora, "o que de fato se interpreta são os encontros de horizontes, que consistem precisamente no que se fala e escuta" (p. 86). O pesquisador/psicólogo, portanto, precisa, em sua busca compreensiva, estar atento à maneira como é afetado e como os outros o são pelos fenômenos que experienciam, levando em conta o horizonte fático em que ambos se encontram.

Cabe relembrar que a tradição, ou o horizonte histórico, determina o modo como compreendemos as coisas, caracterizando nossa pré-compreensão. Assim, ao se realizar uma entrevista de pesquisa, já existe um horizonte prévio de compreensão em que o pesquisador e o pesquisado se encontram, interessando ao pesquisador justamente as novas possibilidades compreensivas que emergem do próprio encontro na medida em que o fenômeno é interrogado/tematizado.

Na hermenêutica heideggeriana adaptada à situação de uma pesquisa clínica, tanto o pesquisador quanto o clínico, ao partirem da própria experiência e condição humana de ser-no-mundo, colocam-se diante do outro considerando o movimento de manifestação da existência que ocorre com a compreensão. Nesse movimento, o ser sempre se revela e se oculta e, quando o ser se revela, pode-se asseverar que houve uma compreensão, isto é, que algo foi iluminado, que um sentido se abriu. Por esse viés, o clínico e o pesquisador, 
movidos por uma atitude fenomenológica, podem ser considerados agentes que possibilitam essa abertura compreensiva de um sofrimento ou de uma experiência que se pretende estudar.

Em Ser e Tempo, Heidegger (2005) denomina o exercer da analítica existencial de Daseinsanalyse, entendendo-o, por analítica, não como uma decomposição em elementos, mas, recorrendo ao seu sentido original do grego Analisein, como o destecer de uma trama, libertar, soltar algo das amarras. A analítica busca, portanto, o desvelamento do fenômeno em seu sentido originário. De acordo com Feijoo (2011), na clínica daseinsanalítica, estão em jogo o tecer e o destecer da trama existencial a partir do horizonte fático sedimentado. Nesse horizonte, o homem costuma colocar-se como aprisionado, determinado, esquecendo-se do seu poder-ser. Dessa feita, a clínica realizada nesses termos possibilita, através da fala/escuta, o destecer, isto é, liberta aquele que está em sofrimento para realizar as suas possibilidades, colocando-o novamente na abertura do sentido. Ao falar, o cliente em análise tematiza suas questões, ou seja, põe-se a refletir sobre as condições existenciais dessas questões (MATTAR; SÁ, 2005). Do mesmo modo, a pesquisa, ao trabalhar com a experiência narrada acerca de uma determinada questão que se propõe a conhecer/compreender, também promove a abertura de sentidos.

Sob esse viés, a tarefa da hermenêutica proposta por Heidegger, e atualizada por seu discípulo Gadamer, é, pois, elucidar o campo histórico compreensivo do Dasein. A verdade aqui não se trata daquilo que é verificado pelo método, mas daquilo que permite desencobrir a tradição, no sentido de clarear os pressupostos que guiam a nossa interpretação. Desencobrir o horizonte histórico não significa se livrar dele, mas a sua elucidação possibilita o aparecimento de novas possibilidades compreensivas que até então se encontravam cristalizadas (PRADO; CALDAS, 2015). Pensando em uma situação de pesquisa orientada por essa perspectiva, tomamos inicialmente os fenômenos em sua familiaridade cotidiana e, posteriormente, para compreendê-los em seu sentido originário, trazemos à luz a história do seu encobrimento, o que somente é possível acompanhando o próprio movimento da existência. Nesse movimento, o fenômeno nunca cessa de ser interrogado, na medida em que o Dasein é um ente que está em jogo em seu poder-ser.

Desse modo, podemos ressaltar que o papel do pesquisador e do clínico é acompanhar esse movimento, estando atento aos sentidos que emergem daquilo que se fala e se escuta em uma via que não é a da razão/logos, mas a da poiesis, permitindo que 
o ente seja. Para Heidegger (2009, p. 263), trata-se de uma tarefa difícil por parte do pesquisador:

[...] a passagem do projeto do homem como ente vivo dotado de razão para ser homem como Dasein. [...]. O "deixar" [Lassen], isto é, aceitar [Zulassen] o ente, assim como ele se mostra, só se tornará um deixar-ser apropriado se este ser, o Da-sein, ficar antes e constantemente à vista; isto é, quando o próprio pesquisador tiver experienciado e experienciar-se a si mesmo como Da-sein, como eksistente e determinar-se toda realidade humana a partir daí.

\section{Considerações finais}

Segundo Sá (2017), a grande contribuição das abordagens hermenêuticas para as ciências de modo geral diz respeito ao seu caráter perspectivista, isto é, ao seu intuito de levar em consideração o horizonte de sentido em que a interpretação do fenômeno se dá, a partir da interação entre intérprete e fenômeno interpretado. A preocupação não se volta a encontrar a interpretação mais real ou verdadeira do fenômeno, mas a trazer à tona as dimensões que uma determinada forma de interpretar pode revelar ou ocultar mediante o próprio horizonte que a possibilita.

A hermenêutica contemporânea - e aqui não nos restringimos somente às contribuições de Heidegger, mas também nos baseamos em Gadamer, Ricoeur e Habermas - não pretende uma absolutização do conhecimento nem uma normatização dos modos de interpretação, na medida em que se reconhece a impossibilidade de uma transparência total de uma interpretação, tendo em vista que os horizontes de compreensão são marcados pela abertura e constante transformação histórica (SÁ, 2017). Em um horizonte marcadamente técnico, pensar hermeneuticamente é não reduzir a dimensão plural e multifacetada dos fenômenos existenciais a um conjunto de causas e leis previamente estabelecidos, como evidencia o próprio Heidegger:

Diferente das ciências, o rigor do pensamento não reside apenas a exatidão artificial, isto é, técnico-teórica dos conceitos. O rigor do pensamento se edifica na medida em que seu dizer permanece, exclusivamente, no elemento do Ser e deixa vigorar a simplicidade de suas múltiplas dimensões. (HEIDEGGER, 1995, p. 27).

A natureza e o homem não podem ser vistos somente como fundos de reserva a serem explorados, medidos e controlados. A técnica moderna acaba impondo o aparecer dos entes, os quais são provocados e desafiados a aparecer como recurso, como matériaprima. No entanto, a proposta heideggeriana é de deixar que o ente apareça e se desvele ao seu próprio modo. Trata-se de um desocultar que acompanha a própria natureza. $\mathrm{O}$ conhecimento aqui "pro-duzido", portanto, não é uma teoria técnica/explicativa sobre um 
fenômeno, mas o seu desencobrimento, a revelação do seu sentido mais originário. E essa pro-dução de sentido revela-se infindável, não sendo possível prever quais serão os seus resultados, já que os fenômenos estão sempre em realização, em um eterno vir-a-ser (CABRAL; MORATO, 2013). A hermenêutica fenomenológica propõe-se justamente a compreender o homem a partir de sua própria existência e em sua facticidade histórica e temporal, sabendo que esse caminho é incompleto, inseguro e, na maioria das vezes, obscuro.

Conforme podemos observar, a pesquisa na perspectiva hermenêutica possui uma origem e um destino ${ }^{9}$ diferentes das pesquisas que buscam a verdade e a representação das coisas via pensamento calculante, o que não significa desvalorizar tais formas de construir conhecimento, mas apenas apontar e valorizar outros modos de se pensar e fazer pesquisa. Alertamos, assim, para o fato de que o método científico tradicional não é a única via de acesso aos fenômenos. Em uma pesquisa orientada pela hermenêutica heideggeriana, o conhecimento produzido refere-se a compreensões possíveis do fenômeno que se interroga via pensamento meditante, considerando o contexto em que a pesquisa se desenvolve e as relações ali estabelecidas. $\mathrm{O}$ pensar meditante mantém desperta a reflexão, na medida em que não pretende nem pode esgotar todas as possibilidades de interpretação de um fenômeno, posto que o ser, ao mesmo tempo que se revela, também se oculta. A esse respeito, Heidegger (2010) nos orienta a apresentarmos diante das coisas uma atitude diferente. Tal atitude é denominada por ele de serenidade, que concerne a uma escuta, a uma atenção solícita ao que está mais próximo e a uma abertura ao mistério, ao desconhecido.

A grande contribuição da hermenêutica heideggeriana para a ação clínica e para a pesquisa em psicologia clínica diz respeito a pensar esse campo para além das intervenções técnicas e prescritivas, assim como compreender, como bem aponta Morato (2013), "o modo der ser psicólogo como humano que é, não pelo modelo de cientista da Psicologia" (p. 51).

\section{Referências}

AMATUZZI, M. M. Pesquisa fenomenológica em psicologia. In: BRUNS, M. A. T.; HOLANDA, A. F. (Orgs.). Psicologia e Fenomenologia: reflexões e perspectivas. 1. ed. Campinas: Editora Alínea, 2003. p. 15-22.

\footnotetext{
${ }^{9}$ Destino compreendido como rumo, direção, sentido.
} 
ANDRADE, C. C.; HOLANDA, A. F. Apontamentos sobre pesquisa qualitativa e pesquisa empírico-fenomenológica. Estud. psicol., Campinas, v. 27, n. 2, p. 259-

268, jun. 2010. Disponível em:

$<$ http://www.scielo.br/scielo.php?script=sci_arttext\&pid=S0103-

166X2010000200013\&lng=en\&nrm=iso>. Acesso em: 30 jan. 2018.

AZEVEDO, A. K. S. Não há você sem mim: histórias de mulheres sobreviventes de uma tentativa de homicídio. 2013. 200 f. Tese (Doutorado em Psicologia) - Universidade Federal do Rio Grande do Norte, Natal, 2013.

BARRETO, C. L. B. T. Reflexões para pensar a ação clínica a partir de Heidegger: da Ontologia fundamental à questão da técnica. In: BARRETO, C. L. B. T.; MORATO, H. T. P.; CALDAS, M. T. (Orgs.). Prática psicológica na perspectiva fenomenológica. 1. ed. Curitiba: Juruá, 2013. p. 27-50.

CABRAL, B. E. B.; MORATO, H. T. P. A questão da pesquisa como bússola: notas sobre o processo de produção de conhecimento em uma perspectiva fenomenológica existencial. In: BARRETO, C. L. B. T.; MORATO, H. T. P.; CALDAS, M. T. (Orgs.). Prática psicológica na perspectiva fenomenológica. 1. ed. Curitiba: Juruá, 2013. p. 159-182.

CASANOVA, M. A. Compreender Heidegger. 1. ed. Petrópolis: Vozes, 2009.

CRITELLI, D. M. Analítica do sentido: uma aproximação e interpretação do real de orientação fenomenológica. 1. ed. São Paulo: Educ Brasiliense, 1996.

DUTRA, E. M. S. Rogers and Heidegger: Is a gathering for a new view of the self possible? Estudos de Psicologia, Campinas, v. 33, n. 3, p. 413-423, jul./set. 2016. Disponível em: $<$ http://www.scielo.br/scielo.php?script=sci_arttext\&pid=S0103166X2016000300413\&lng=en\&nrm=iso>. Acesso em: 31 jan. 2018.

DUTRA, E. M. S. A narrativa como uma técnica de pesquisa fenomenológica. Estudos de Psicologia, Natal, v.7, n. 2, p. 371-378, jul. 2002. Disponível em: $<$ http://www.scielo.br/scielo.php?script=sci_arttext\&pid=S1413294X2002000200018\&lng=en\&nrm=iso>. Acessos em: 31 jan. 2018.

FEIJOO, A. M. C. A escuta e a fala em psicoterapia: uma proposta fenomenológicoexistencial. 2. ed. Rio de Janeiro: IFEN, 2010.

FEIJOO, A. M. C. A existência para além do sujeito: a crise da subjetividade moderna e suas repercussões para a possibilidade de uma clínica psicológica com fundamentos fenomenológicoexistenciais. 1.ed. Rio de Janeiro: Edições IFEN: Via Verita, 2011.

FERREIRA, L. da S. M. Entre a Fenomenologia e a Hermenêutica: uma perspectiva em psicoterapia. Revista da abordagem gestáltica, Goiânia, v. 15, n. 2, p. 143148, dez. 2009. Disponível em: $<$ http://pepsic.bvsalud.org/scielo.php?script=sci_arttext\&pid=S180968672009000200010\&lng=pt\&nrm=iso>. Acesso em: 30 jan. 2018.

FROTA, A. M. M. C. O rigor na pesquisa fenomenológica com orientação heideggeriana. In: SEMINÁRIO INTERNACIONAL DE PESQUISA E ESTUDOS QUALITATIVOS, 4, 2010, Rio Claro, São Paulo. Anais... Rio Claro, SP, 2010. p. 1-8.

GOTO, T. A. Introdução à psicologia fenomenológica: a nova psicologia de Edmund Husserl. 1. ed. São Paulo: Paulus, 2008. 
HOLANDA, A. F. Pesquisa fenomenológica e psicologia eidética: elementos para um entendimento metodológico. In: BRUNS, M. A. T.; HOLANDA, A. F. (Orgs.). Psicologia e Fenomenologia: reflexões e perspectivas. 1.ed. Campinas, SP: Editora Alínea, 2003. p. 41-64.

HOLANDA, A. F. Fenomenologia e humanismo: reflexões necessárias. 1.ed. Curitiba: Juruá, 2014.

HEIDEGGER, M. Ser e tempo: parte I. Tradução de Márcia Sá Cavalcante Schuback. 3. ed. Petrópolis: Vozes, 1989.

HEIDEGER, M. Ser e tempo: parte II. Tradução de Márcia Sá Cavalcante Schuback. 15. ed. Petrópolis: Vozes, 2005.

HEIDEGGER, M. Seminários de Zollikon: protocolos - diálogos - cartas. Traduçã de Gabriella Arnhold, Maria de Fátima de Almeida Prado e Renato Kirchner. 3. ed. Petrópolis: Vozes, 2009.

HEIDEGGER, M. Ensaios e conferências. Tradução de Emanuel Carneiro Leão, Gilvan Fogel e Márcia Sá Cavalcante Schuback. 6. ed. Petrópolis, RJ: Vozes, 2010.

HEIDEGGER, M. Ser e tempo. Tradução de Márcia Sá Cavalcante Schuback. 8. ed. Petrópolis: Vozes; Bragança Paulista: Editora Universitária São Francisco, 2013a.

HEIDEGGER, M. Ontologia (hermenêutica da facticidade). Trad. Renato Kirchner. 2. ed. Petrópolis: Vozes, 2013b.

MATTAR, C. M.; SÁ, R. N. Os sentidos de "análise" e "analítica" no pensamento de Heidegger e suas implicações para a psicoterapia. Revista de Psicologia da UERJ, Rio de Janeiro, v. 8, n. 2, p. 191-203, ago. 2005. Disponível em: $<$ http://pepsic.bvsalud.org/scielo.php?script=sci_arttext\&pid=S1808$42812008000200005 \& \operatorname{lng}=$ pt\&nrm=iso>. Acesso em: 31 jan. 2018.

MAUX, A. A. B. Masculinidade à prova: um estudo de inspiração fenomenológicohermenêutico sobre a infertilidade masculina. 2014. 161 f. Tese (Doutorado em Psicologia) Universidade Federal do Rio Grande do Norte, Natal, 2014.

MELO, R. F. Entre compreensão e interpretação: para uma hermenêutica filosófica no pensamento de Heidegger. Ekstasis: Revista de Fenomenologia e Hermenêutica, Rio de Janeiro, v. 2, n. 1, p. 84-99, 2013. Disponível em: <http://www.epublicacoes.uerj.br/index.php/Ekstasis/article/view/7368>. Acesso em: 31 jan. 2018.

MORATO, H. T. P. Atenção psicológica e aprendizagem significativa. In: MORATO, H.T.P.; BARRETO, C. L. B. T.; NUNES, A. P. Aconselhamento psicológico numa perspectiva fenomenológica existencial. 1.ed. Rio de Janeiro: Guanabara/Koogan. 2009. p. 22-40.

MORATO, H. T. P. Algumas considerações da fenomenologia existencial para a ação psicológica na prática e na pesquisa em instituições. In: BARRETO, C. L. B. T.; MORATO, H.T.P.; CALDAS, M. T. (Orgs.). Prática psicológica na perspectiva fenomenológica. Curitiba: Juruá, 2013. p. 51-76.

POMPÉIA, J. A.; SAPIENZA, B. L. Na presença do sentido: uma aproximação fenomenológica a questões existenciais básicas. 1.ed. São Paulo: EDUC/Paulus, 2004.

PRADO, R. A. de A.; C., M. T. Hermenêutica filosófica, fenomenologia e narrativa: percurso metodológico de uma pesquisa em psicologia clínica. Revista Psicologias, Rio Branco, v. 1, p. 
1-25, abr. 2015. Disponível em:

<http://revistas.ufac.br/revista/index.php/psi/article/view/207/0>. Acesso em: 31 jan. 2018.

RAFAELLI, R. Husserl e a psicologia. Estudos de Psicologia, Natal, v. 9, n. 2, p. 211-215, ago. 2004. Disponível em: <http://www.scielo.br/scielo.php?script=sci arttext\&pid=S1413294X2004000200002\&lng=en\&nrm=iso>. Acesso em: 31 jan. 2018.

REBOUÇAS, M. S. S. Aborto: um fenômeno sem lugar - uma experiência de plantão psicológico para mulheres em situação de abortamento. 2015. 197 f. Tese (Doutorado em Psicologia) - Universidade Federal do Rio Grande do Norte, Natal, 2015.

REBOUÇAS, M. S. S; DUTRA, E. M. S. O aborto provocado como uma possibilidade na existência da mulher: reflexões fenomenológico-existenciais. Revista Natureza Humana, São Paulo, v.14, n. 2, p.192-219, 2012. Disponível em:

<http://pepsic.bvsalud.org/scielo.php?script=sci_arttext\&pid=S151724302012000200010\&lng=pt\&nrm=iso>. Acesso em: 31 jan. 2018.

REBOUÇAS, M. S. S. O aborto provocado como uma possibilidade na existência da mulher: reflexões fenomenológico-existenciais. 2010. 145 f. Dissertação (Mestrado em Psicologia) - Universidade Federal do Rio Grande do Norte, Natal, 2010.

ROEHE, M. V. Uma abordagem fenomenológico-existencial para a questão do conhecimento em psicologia. Estudos de Psicologia, v. 11, n. 2, p. 53-158, 2005. Disponível em http://www.scielo.br/scielo.php?script=sci arttext\&pid=S1413294X2006000200004\&lng=en\&nrm=iso. Acesso em: 31 jan. 2018. http://dx.doi.org/10.1590/S1413-294X2006000200004.

SÁ, R. N. A psicoterapia e a questão da técnica. Arquivos Brasileiros de Psicologia. Rio de Janeiro, v. 54, n. 2, p. 348-362, out./dez. 2002.

SÁ, R. N. Para além da técnica: ensaios fenomenológicos sobre psicoterapia, atenção e cuidado. 1. ed. Rio de Janeiro: Via Verita, 2017.

SÁ, R. N.; BARRETO, C. L. B. T. A noção fenomenológica de existência e as práticas psicológicas clínicas. Estudos de Psicologia, Campinas, v.28, n. 3, p. 389-394, set. 2011. Disponível em: <http://www.scielo.br/scielo.php?script=sci arttext\&pid=S0103166X2011000300011\&lng=en\&nrm=iso>. Acesso em: 31 jan. 2018.

STEIN, E. A questão do método na filosofia: um estudo do modelo heideggeriano. 2. ed. Porto Alegre: Movimento, 1983.

Recebido em: 31 de janeiro de 2018.

Aceito em: 02 de julho 2018. 